\title{
STEM CELL-BASED APPROACHES IN DENTISTRY
}

\author{
T.A. Mitsiadis ${ }^{1 *}$, G. Orsini ${ }^{2}$ and L. Jimenez-Rojo ${ }^{1}$ \\ ${ }^{1}$ Orofacial Development and Regeneration, Institute of Oral Biology, Centre for Dental Medicine, Medical Faculty, \\ University of Zurich, Zurich, Switzerland \\ ${ }^{2}$ Department of Clinical Sciences and Stomatology, Polytechnic University of Marche, Ancona, Italy
}

\begin{abstract}
Repair of dental pulp and periodontal lesions remains a major clinical challenge. Classical dental treatments require the use of specialised tissue-adapted materials with still questionable efficacy and durability. Stem cell-based therapeutic approaches could offer an attractive alternative in dentistry since they can promise physiologically improved structural and functional outcomes. These therapies necessitate a sufficient number of specific stem cell populations for implantation. Dental mesenchymal stem cells can be easily isolated and are amenable to in vitro expansion while retaining their stemness. In vivo studies realised in small and large animals have evidenced the potential of dental mesenchymal stem cells to promote pulp and periodontal regeneration, but have also underlined new important challenges. The homogeneity of stem cell populations and their quality control, the delivery method, the quality of the regenerated dental tissues and their integration to the host tissue are some of the key challenges. The use of bioactive scaffolds that can elicit effective tissue repair response, through activation and mobilisation of endogenous stem cell populations, constitutes another emerging therapeutic strategy. Finally, the use of stem cells and induced pluripotent cells for the regeneration of entire teeth represents a novel promising alternative to dental implant treatment after tooth loss. In this mini-review, we present the currently applied techniques in restorative dentistry and the various attempts that are made to bridge gaps in knowledge regarding treatment strategies by translating basic stem cell research into the dental practice.
\end{abstract}

Keywords: tooth, dental stem cells, mesenchymal stem cells, induced pluripotent cells, tooth regeneration, regenerative dentistry, clinical trials.

*Address for correspondence:

Thimios Mitsiadis, DDS, PhD

University of Zurich, Faculty of Medicine, Orofacial Development and Regeneration,

Institute of Oral Biology, ZZM,

Plattenstrasse 11, 8032 Zurich, Switzerland

Telephone number: +41446343390

Fax number: +41 446344310

E-mail: thimios.mitsiadis@zzm.uzh.ch

\section{Introduction}

The tooth is composed of the highly mineralised tissues of enamel, dentin and cementum, as well as by the soft connective tissues of dental pulp and periodontium (Mitsiadis and Graf, 2009; Nanci, 2012). Enamel is formed by the epithelium-derived ameloblasts, while ectomesenchymal cells give rise to all other tooth components. Dental pulp cells differentiating into odontoblasts produce the dentin matrix, while periodontal cells are involved in cementum and alveolar bone formation. The periodontal space contains specific fibres (i.e., periodontal ligament fibres) that stabilise teeth, since they connect root cementum to the alveolar bone, as well as a variety of cell types such as fibroblasts, epithelial rests of Malassez, neuronal and endothelial cells (Mariotti, 1993; Sonoyama et al., 2007).

Traumatic injuries, periodontal disease and caries are mainly responsible for pathologies affecting teeth and their surrounding tissues (Caton et al., 2011). These pathologies remain a major clinical challenge, due mainly to the limited self-healing capability of dental tissues. The reparative mechanisms following dental or periodontal lesion involve highly conserved genetic programs that are active during embryonic tooth development (Aberg et al., 1997; About and Mitsiadis, 2001; Giannobile and Somerman, 2003; Jin et al., 2004; Magloire et al., 2001; Mitsiadis and Rahiotis, 2004; Ripamonti, 2007). For example, in severe dental pulp injury or inflammation (i.e., pulpitis), stem cells or/and progenitors give rise to a new generation of odontoblasts that replace the disintegrated odontoblasts. Signalling molecules released at the pathologic sites may attract these stem cells and progenitors, thus initiating the healing process that includes the reparative dentin formation (Nakashima and Iohara, 2014). However, the reparative capability of the dental pulp and periodontium is often insufficient to restore the totality of the damaged tissues. If untreated, these lesions compromise tooth integrity that can lead to more severe pathologies and tooth loss.

The increased knowledge on the reparative events within dental tissues has contributed to the proposal of alternative methods for the treatment of dental pathologies. However, traditional treatments continue to be applied in dental clinics since most of the proposed therapeutic approaches are still at the experimental level. For example, partial dental tissue repair techniques involve specialised dental materials with uncertain effectiveness and durability, while high-tech dental implants are used for tooth replacement (Esposito et al., 2013; Fron Chabouis et al., 2013). These materials are often used in conjunction with growth factors and molecules to enhance the regenerative capacity of dental and periodontal tissues (Pilipchuk et al., 2015). Recent advances in tissue engineering and regenerative 
medicine offer the potential for a long-term solution by means of biological repair or replacement of damaged teeth. The aim of this mini-review is to present the currently applied tissue repair techniques and their limitations in restorative dentistry and to introduce stem cell-based approaches as promising tools for the regeneration of injured and pathological teeth. Therefore, the different sources of dental stem cells, their differentiation potential and the current state of stem cell-based strategies for dental tissue regeneration are discussed. From a translational point of view, we summarise the various preclinical models used for the evaluation of stem cell-based therapies in dentistry and report on the recent developments and challenges related to clinical applications of human stem cells in situations that necessitate pulp and periodontal tissue regeneration.

\section{Current therapeutic interventions in dentistry}

Contemporary techniques to replace damaged dental hard tissues consist of direct tooth restorations using resin-based composites, or indirect restorations using composite or ceramic inlays and onlays (Ferracane, 2011; Fron Chabouis et al., 2013). While adhesion of these materials to enamel is stable over time, adhesion to dentin is weaker and unstable because of the higher levels of organic matrix of dentin when compared to enamel (Lehmann et al., 2009).

Endodontic therapy is a procedure implying the removal of contaminated or necrotic dental tissues within the pulp. In case of pulp exposure or infection, the damaged part of the pulp has to be removed, leaving intact the healthy part of the pulp at the tooth root level, a process called pulpotomy (DeRosa, 2006). In selected cases, this method preserves the vitality of pulp located at the root canal, thus allowing the accomplishment of the root growth (Fuks, 2008). Traditionally, the damaged pulp is entirely replaced with inorganic materials such as gutta-percha, after root canal treatment (Ricketts, 2001). Since dental pulp provides nutrition, sensation, and defence against the various pathogens, devitalised teeth are subject to various complications causing tooth fragility and fracture (Ricketts, 2001). Therefore, maintaining of dental pulp vitality is of prime importance and this is highlighted by the emergence of new stem cell-based techniques focusing on pulp regeneration (Potdar and Jethmalani, 2015).

Currently, missing teeth are replaced with dental implants (Esposito et al., 2013). Their retention requires close contact of implants with the alveolar bone, a process called osseointegration (Branemark et al., 1977). Most of dental implants are made of biocompatible titanium alloy and they are inserted into the bone after surgical intervention. The clinical success of implants depends on alveolar bone quality and dimensions, primary implant stability, time of masticatory loading, infections, and implant surface characteristics (Esposito et al., 2013; Esposito et al., 2007). Recent regenerative technologies using scaffolds, stem cells, and growth factor delivery have enhanced host tissue response and implant osseointegration (Naddeo et al., 2015; Pilipchuk et al., 2015). Recent clinical trials have demonstrated that stem cells seeded in specific scaffolds are able to generate adequate amounts of bone in order to achieve primary implant stability (Kitamura et al., 2011; Windisch et al., 2012). These new approaches are contributing to the progress of dental treatments, but should be further studied using controlled randomised clinical trials.

\section{Stem cells within teeth}

The theoretical basis for dental tissue repair is the activation of stem and progenitor cells that will enhance the regenerative process (Bluteau et al., 2008; Caton et al., 2011). Mesenchymal stem cells (MSCs) were originally isolated from bone marrow (Friedenstein et al., 1970). MSCs are fibroblast-like cells capable of adhering to plastic dishes, to form colonies derived from single cells (colony forming unit fibroblasts), and to differentiate into mature cells of mesenchymal lineages such as osteoblasts and chondrocytes (Caplan and Bruder, 2001; Friedenstein et al., 1970; Pittenger et al., 1999; Prockop, 1997; Sudo et al., 2007; Weissman et al., 2001). The discovery that human adult teeth contain cells with similar functions to MSC indicated that these organs are important reservoirs of adult stem cell populations (Gronthos et al., 2000). Therefore, dental mesenchymal stem cells (DMSCs) can be used for regeneration of teeth, or other organs that have limited intrinsic repair potential (Di Scipio et al., 2014; Gandia et al., 2008; Graziano et al., 2008; Kerkis et al., 2008; Nosrat et al., 2001). Besides their capacity to give rise to various cell types such as chondrocytes, osteocytes and adipocytes (Bluteau et al., 2008; Gronthos et al., 2000), DMSCs may act as cellular modulators to support endogenous reparative mechanisms tissue by secretion of bioactive molecules (Choi and Reddy, 2014; van den Akker et al., 2013).

Cultures of DMSCs and MSCs are indistinguishable, and at present no markers permit selective identification of either cell type from culture-expanded DMSC populations (Pagella et al., 2015). Likewise, it is not yet known whether DMSC properties reside in distinct cell subpopulations. Similarly to MSCs, DMSCs are heterogeneous in their phenotype, and this could possibly reflect a coexistence of functionally distinct cell subsets (Jiang et al., 2002; Muraglia et al., 2000). Markers alone would not be sufficient to rule out the presence of other than DMSCs within dental tissues. Studies using single cell-derived clonal populations will be needed to determine whether DMSCs differentiation potency is inherent in individual cells from dental tissues.

Despite similar phenotypic characteristics, DMSCs from different locations have significant functional heterogeneity both in vitro and in vivo, thus indicating distinct physiological roles within teeth (Caton et al., 2011; Pagella et al., 2015). In the dental pulp, DMSCs are located mainly in two niches: the apical niche and the perivascular niche (Mitsiadis et al., 2011; Zhao et al., 2014). In these two niches, DMSCs could have distinct functions and still be geographically interchangeable, but a temporo-spatial hierarchy between the two DMSC niches remains to be investigated. Furthermore, the identification 


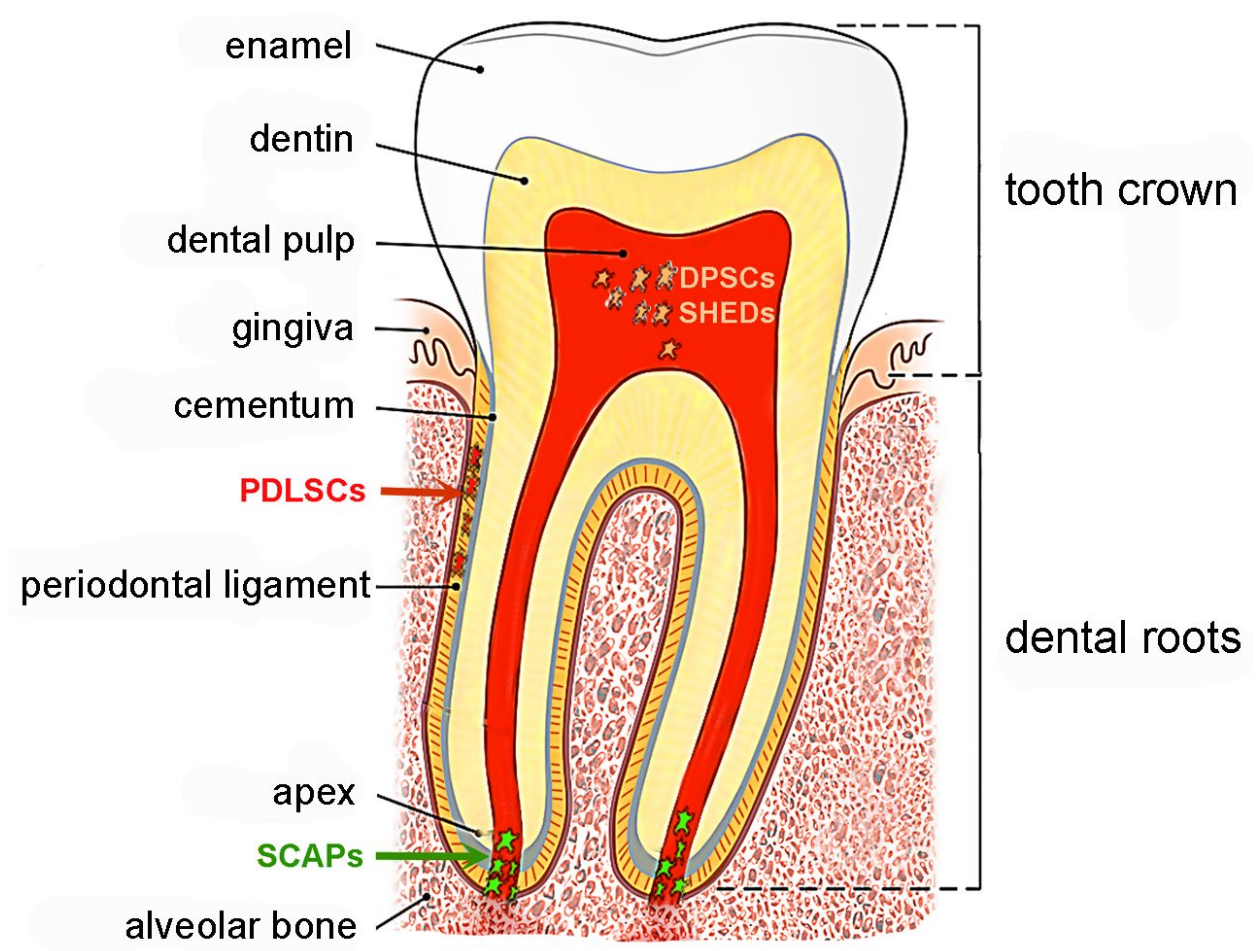

Fig. 1. Schematic representation of the main populations of mesenchymal stem cells found in human teeth. Abbreviations: DPSCs, dental pulp stem cells; PDLSCs, periodontal ligament stem cells; SCAPs, stem cells from the apical papilla; SHEDs, stem cells from human exfoliated deciduous teeth.

and characterisation of other dental stem cell niches, and the examination of how niche-derived signals are orchestrated towards tooth homoeostasis and repair is of prime importance.

The developmental origins of DMSCs in adult teeth are not known yet. They could be directly derived from dental tissues (e.g., pulp, periodontium), but a contribution from blood-derived circulating MSCs has not to be excluded. Indeed, MSCs are found in the circulation and are likely to engraft in all tissues of the body (Kuroda et al., 2014; Lemoli et al., 2006). The embryonic origins of circulating MSCs are different from those of DMSCs (La Noce et al., 2014; Pagella et al., 2015), thus suggesting distinct properties and functions for these two stem cell populations. The various dental stem cell populations and their potencies are described in Fig. 1.

Dental pulp stem cells (DPSCs) were first isolated from human teeth in 2000 and are the most common source of DMSCs (Gronthos et al., 2000). Due to the lack of specific DMSCs markers, generic MSC markers such as STRO-1, CD146 and CD44 are commonly used for the isolation and identification of DMSCs (Pittenger et al., 1999). DPSCs are capable of differentiating into odontogenic (Gronthos et al., 2000; Hayashi et al., 2015; Miura et al., 2003), osteogenic (d'Aquino et al., 2009; de Mendonca Costa et al., 2008), chondrogenic (Waddington et al., 2009), adipogenic (Gronthos et al., 2002; Waddington et al., 2009), myogenic (Kerkis et al., 2008; Pisciotta et al., 2015), and neurogenic (Martens et al., 2014; Nosrat et al., 2001) cells in vitro and in vivo.
Stem cells from human exfoliated deciduous teeth (SHEDs) are isolated using the same procedure as for DPSCs. SHEDs express the surface molecules STRO-1 and CD146, and several neural and glial markers such as nestin and $\beta$-III tubulin (Miura et al., 2003). SHEDs proliferate very fast, are capable of differentiating into odontogenic, osteogenic, chondrogenic, adipogenic, myogenic, and neurogenic cells in vitro, and induce bone and dentin formation in vivo (Kerkis et al., 2008; Miura et al., 2003).

Stem cells from the apical part of the dental papilla (SCAPs) are located at the root apex of the developing teeth, are highly proliferative, and exhibit increased migratory and regenerative potentials (Sonoyama et al., 2006; Sonoyama et al., 2008). SCAPs express the same DMSCs surface markers, as well as CD24 for which DPSCs are negative, and are able to form dentin in vivo (Huang et al., 2009; Sonoyama et al., 2006).

Periodontal ligament stem cells (PDLSCs) express the cell-surface markers STRO-1, CD146 and CD44, and are able to differentiate into adipogenic and osteogenic cells, under defined culture conditions in vitro (Seo et al., 2004). PDLSCs can contribute to the regeneration of the periodontium by giving rise to cementum and PDL tissues in vivo (Seo et al., 2004). Alveolar periodontal ligament stem cells (aPDLSCs) form another PDLSC population that locates close to the alveolar bone and shows great osteogenic and adipogenic capabilities (Wang et al., 2011).

Stem cells from the dental follicle (DFSCs) are progenitor cells for the PDL, alveolar bone, and cementum, and express the STRO-1 and CD44 markers (Morsczeck 
et al., 2005). DFSCs are able to form cementum and bone tissues in vitro and in vivo (Kemoun et al., 2007; Yokoi et al., 2006).

Human dental epithelial stem cells (hDESCs) can be isolated from the third molar that develops late after birth (Honda et al., 2007; Honda et al., 2005). Another source of hDESCs is the epithelial root sheath that disintegrates into strands of epithelial cells, also known as epithelial rests of Malassez (ERM). ERM cells express epithelial stem cell markers such as Bmi-1, E-CAM, and p75, as well as embryonic stem cell markers such as Oct-4 and Nanog (Nam et al., 2011).

Induced pluripotent stem cells (iPSCs) may represent another source of hDESCs. Indeed, iPSCs have the capacity to differentiate into various cell lineages (Takahashi and Yamanaka, 2006) and can be technically produced from patient's cells. iPSCs technology can be progressively applied for the regeneration of dental tissues. iPSCs are able to differentiate into ameloblast-like cells in the presence of ameloblastin expressing cells (Arakaki et al., 2012). Also, iPSCs are capable of differentiating into mesenchymal odontogenic cells (Otsu et al., 2014).

\section{Stem cell-based regenerative treatments in dentistry}

Although basic research into dental stem cells is well documented, only very recently efforts are emerging to bridge the gap with translational research. Regenerative dentistry aims to regenerate the damaged dental tissues and to fully restore tooth anatomy and function. The functions of exogenously administered dental stem cells go beyond their differentiation potential and the replacement of cells lost due to injury or disease. Dental stem cells may create a repair-conducive microenvironment, stimulating the recruitment of endogenous stem cells or progenitors at the injury site. This insinuates that accurately designed bioactive scaffolds could generate effective dental tissue repair responses through activation and mobilisation of endogenous stem and progenitor cells, thus avoiding exogenous stem cell administration (Hayashi et al., 2015; Lee et al., 2010; Mitsiadis et al., 2012). Such innovative strategies would be easier to apply clinically and likely to encounter fewer regulatory obstacles. This raises the possibility of repairing entire dental tissues through stimulation of endogenous dental stem and progenitor cells. However, several studies in other organs - exploring the possibility of repairing tissues with the exclusive usage of scaffolds impregnated with chemotactic or growth factors - gave uncertain results, judging by the irregular and fibrotic appearance of the regenerated tissue (Lee et al., 2010; Zhang et al., 2013).

The main approaches using stem cells for the repair of specific dental tissue, such as the pulp and the periodontium as well as for entire tooth regeneration, are described in Fig. 2.

\section{Regeneration of pulp-dentin complex}

Regenerative endodontics represents a new treatment modality that relies on the intracanal delivery of stem cells and focuses on re-establishment of pulp vitality and continued root development (Chrepa et al., 2015; Peters, 2014). Numerous attempts, using human DMSCs (hDPSCs), have been made in a variety of animal models in order to achieve complete pulp regeneration. Proper regeneration requires re-vascularisation and re-innervation of the pulp and allows new dentin formation (Peters, 2014). The very first experimental study using hDMSCs showed that these cells can differentiate into odontoblasts, which form dentin-like structures when transplanted together with HA/TCP ceramic powder in immunocompromised mice ex vivo (Gronthos et al., 2000) (Fig. 2). Other, more recent studies, using hDPSCs and SCAPs seeded on polyD,L-lactide/glycol scaffolds have confirmed the ability of human DMSCs to regenerate vascularised pulp tissues when transplanted into the empty mouse tooth root canal (Hayashi et al., 2015; Huang et al., 2010; Volponi et al., 2010) (Fig. 2). However, these experimental attempts using DMSCs transplantation were performed in ectopic locations and therefore, stem cell-based therapeutic approaches for entire pulp regeneration cannot be directly translated into the clinics. For this reason, new experimental strategies have been elaborated, where DMSCs or other stem cell population, combined with scaffolds and/or bioactive molecules, fully fill the empty pulp chamber after pulpotomy (partial pulp removal) or pulpectomy (total pulp removal) (Iohara et al., 2011; Iohara et al., 2013; Zheng et al., 2012 ; Chrepa et al., 2015; Lovelace et al., 2011) (Fig. 2). Indeed, DPSCs transplanted together with granulocytecolony stimulating factor (G-CSF), in pulpectomised teeth of dogs, were able to regenerate the entire pulp and to form new dentin (Iohara et al., 2013). Similarly, bone morphogenetic proteins (BMPs) were used, a long time ago, in order to stimulate the regenerative response of the pulp. While these procedures appear to improve tissue regeneration, their true effectiveness for achieving durable repair is still unclear. For example, the fibrotic tissue that has been obtained in experiments focusing on dental pulp regeneration may not sustain a long-lasting therapeutic effect. Indeed, this fibrous pulp tissue can undergo degeneration over time or be replaced with bone.

Recent regenerative endodontic procedures that have been successfully applied in clinics are based on the bleeding technique, where the blood clot acts as a scaffold that delivers MSCs into the root canal of both immature teeth with pulp necrosis and mature teeth with apical lesions (Chrepa et al., 2015; Deepak and Nandini, 2012; Lovelace et al., 2011; Sonmez et al., 2013). However, the current status of stem cell-based endodontic therapy is still characterised by an empirical approach (Peters, 2014).

\section{Regeneration of periodontal tissues}

Human PDLSCs have been shown to improve periodontal tissue regeneration when transplanted into immunocompromised mice, indicating their big potential for future cell-based therapies in dentistry (Seo et al., 2004) (Fig. 2). The regenerative potential of autologous and allogeneic PDLSCs, as well as of DPSCs, SHEDs and bone marrow stem cells for the treatment of periodontitis has been also demonstrated in other animal models, such as the miniature swine and dog models (Ding et al., 2010; Du et al., 2014; Fu et al., 2014; Khorsand et al., 2013). In 
Regeneration of
dentin-pulp complex in
pulpotomised tooth

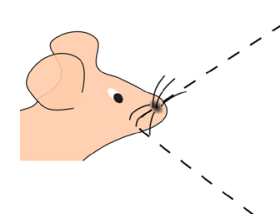

Transplantation of ' DSCs into injured dental tissues

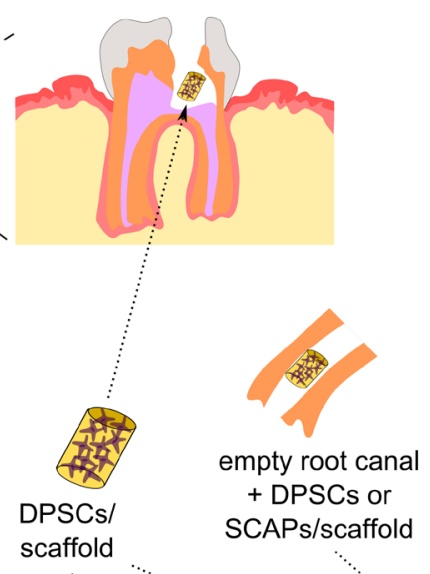

Regeneration of periodontal ligament

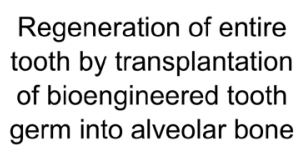

Regeneration of entire tooth by transplantation
of bioengineered tooth germ into alveolar bone
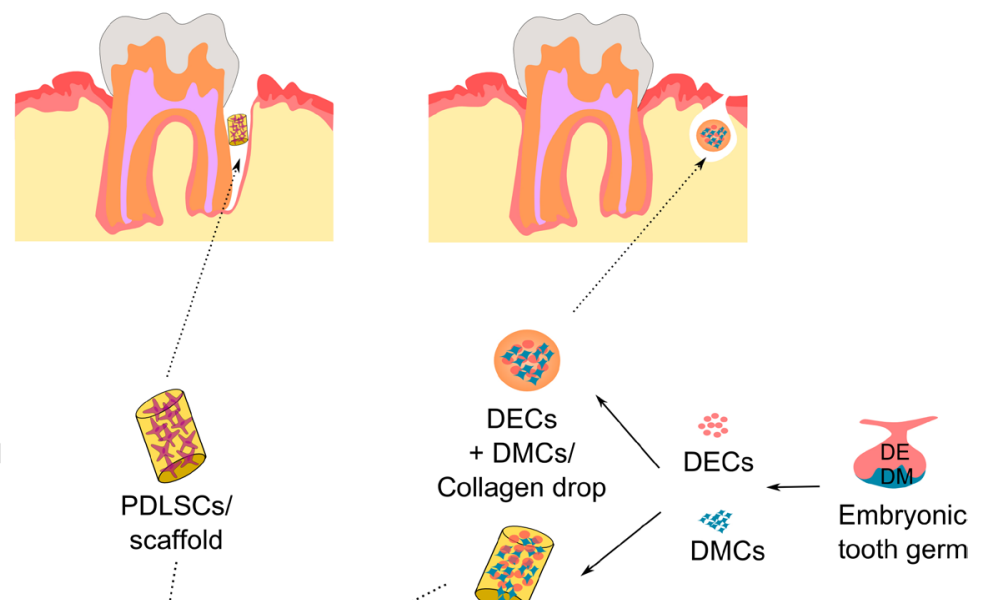

DECs

+ DMCs/

Dissociated cells

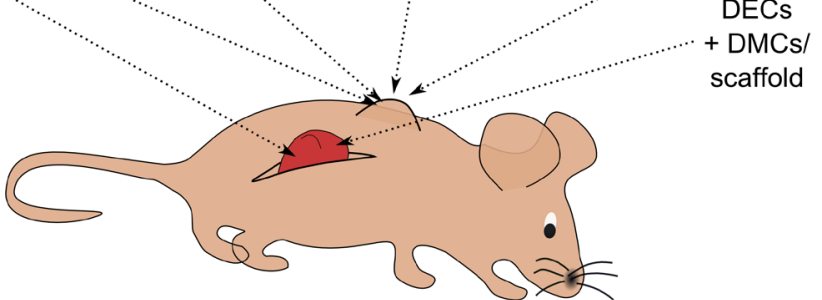

Transplantation of DSCs under kidney capsule or dorsal skin

of immunocompromised mice

Fig. 2. Schematic representation of various stem cell-based strategies used for dental pulp, periodontium, and entire tooth regeneration. Transplantation of stem cells combined with scaffolds in the kidney or dorsal skin of immunocompromised mice is commonly used for regenerative purposes. Abbreviations: DE, dental epithelium; DM, dental mesenchyme; DECs, dental epithelial cells; DMCs, dental mesenchymal cells; DMSCs, dental mesenchymal stem cells; DPSCs, dental pulp stem cells; DSCs, dental stem cells; PDLSCs, periodontal ligament stem cells; SCAPs, stem cells from the apical papilla.

an attempt of improving stem cell-based therapies, growth factors such as platelet-derived growth factors (PDGFs) and BMPs have been used. PDGFs have been proven to stimulate periodontal regeneration (Howell et al., 1997; Lynch et al., 1989), while BMPs enhance alveolar bone and cementum formation (Selvig et al., 2002). However, BMPs may have undesirable effects on periodontal tissues and provoke tooth ankylosis. Commercialised amelogenin extracts have been also used in dental clinics with success for periodontal tissue regeneration, but their mode of action is still unclear (Veis et al., 2000).

Regeneration of alveolar bone defects, caused by periodontal diseases, is one of the major challenges for clinicians. The first clinical trial using autologous human DPSCs, combined with collagen scaffolds, for alveolar bone reconstruction was performed successfully several years ago (d'Aquino et al., 2009). However, a three years follow-up study using in-line holotomography and conventional evaluation procedures has shown that the regenerated bone at the grafted sites was entirely compact and thus completely different from the normal spongy alveolar bone found in the mandibles (Giuliani et al., 2013). Another study, with a significant and stable clinical outcome, was performed in a patient suffering from advanced periodontitis. Autologous bone marrow mononuclear cells (BMMNCs) embedded in a thermoreversible gelation polymer scaffold were used successfully for alveolar bone regeneration, which was validated by clinical and radiographic evaluation in this three year follow-up trial (Sankaranarayanan et al., 2013).

\section{Regeneration of the entire tooth}

Regeneration of the entire tooth would be the ideal therapeutic approach after tooth loss. The association of DESCs and DMSCs in vitro allows the formation of tooth germs that can be transplanted into the alveolar bone, where the germs will develop, erupt, and finally become functional teeth (Ikeda and Tsuji, 2008) (Fig. 2). In a similar assay, dental bud cells were seeded into plateletrich fibrin scaffolds for tooth regeneration in the miniature swine model (Yang et al., 2012). Another approach to obtain new brand teeth is the implantation into the jaw of tooth-shaped polymeric biodegradable scaffolds filled with DESCs and DMSCs (Oshima and Tsuji, 2014) (Fig. 
2). The three-dimensional structure of the scaffolds should drive the differentiation of the transplanted stem cells into odontoblasts and ameloblasts. Indeed, bioengineered teeth using human stem cells have been formed, but only in ectopic sites, to date. Furthermore, these teeth are missing some essential tooth elements such as correct crown morphology and accomplished root formation. However, recent experiments in mice, using bioengineered approaches, have showed that it is possible to obtain functional teeth with entire roots (Oshima and Tsuji, 2014). In fact, tooth germs formed by dental epithelial and mesenchymal cells seeded into collagen drops gave rise to new functional teeth after their implantation into the mandible of adult mice. Formation of all dental tissues allows the eruption and full integration of these teeth into the recipient alveolar bone.

Recent studies have shown that re-aggregation of iPSCs-derived neural crest cells and mouse odontogenic epithelial tissues results to the generation of entire teeth ex vivo (Otsu et al., 2014). Although further technical improvements may be needed, the iPSCs technology is expected to open new horizons in regenerative dentistry.

However, such results have not yet been obtained with human cells. Various populations of human DMSCs are still under investigation, while human DESCs have not been fully studied. Moreover, time represents a great challenge for tooth regeneration: the whole process of odontogenesis in humans takes more than 7 years. This long-term physiological procedure may be discouraging for individuals missing teeth and look forward to immediate treatment outcomes.

\section{Conclusions and perspectives}

During recent decades, several stem cell lines with significant variability in potency have been isolated from human adult teeth. Considerable heterogeneity exists between individual cells isolated from the same dental stem cell pool that may affect the clinical outcomes. Therefore, the identification and purification of stem cell subpopulations with improved potency is a necessary step before application of cell-based treatment in dental clinics. In addition to the choice of dental stem cell populations, a variety of factors such as the lesion size and depth, health status of the surrounding tissues, as well as the delivery methods are also likely to impact on the success of therapy. There is still a need for understanding the mechanisms that control the fates and functions of stem cells after their transplantation into the pathological or injured dental pulp and/or periodontal tissues. Although applications using dental stem cells for pulp and periodontal regeneration have been reported in animal models, the number of clinical trials with long-term follow-up is very limited, if not inexistent. The translation of basic and preclinical stem cell research to the dental clinics is very slow, since technical, safety, regulatory and ethical concerns exist. It is obvious that patients will not benefit from these regenerative treatments until most of the above mentioned issues and concerns will be resolved, and the possible clinical restrictions will be well examined and taken seriously into consideration.
Several clinical trials using autologous stem cells for pulp and periodontal tissue regeneration have already been approved and initiated, but the outcome of these studies has not yet been communicated. For example, a clinical trial sponsored by the Fourth Military Medical University in China will evaluate the effects of PDLSCs in periodontal tissue regeneration (https://clinicaltrials.gov/ct2/show/ NCT01357785). Similarly, another clinical trial in Japan deals with dental pulp regeneration by transplantation of autologous pulp stem cells (http://www.stemcellsaustralia. edu.au/About-Stem-Cells/Stem-Cell-Clinical-Trials/ Dental-treatments/Periodontitis.aspx).

It is obvious that stem cell-based regenerative approaches in dentistry are just at the beginning, but have the potential to benefit millions of patients worldwide. Other emerging technologies, such as nanotechnology, imaging systems and mathematical modelling should be incorporated in the stem cell research field in order to obtain faster, reliable and qualitative advancements and outcomes in dental clinics.

\section{Acknowledgments}

This work was supported by funds of the University of Zurich (TM and LJR) and the Polytechnic University of Marche (GO). The authors contributed to the planning, writing, critical reading, and editing of the manuscript. The authors confirm that there are no conflicts of interest associated with this work.

\section{References}

Aberg T, Wozney J, Thesleff I (1997) Expression patterns of bone morphogenetic proteins (BMPs) in the developing mouse tooth suggest roles in morphogenesis and cell differentiation. Dev Dyn 210: 383-396.

About I, Mitsiadis TA (2001) Molecular aspects of tooth pathogenesis and repair: in vivo and in vitro models. Adv Dent Res 15: 59-62.

Arakaki M, Ishikawa M, Nakamura T, Iwamoto T, Yamada A, Fukumoto E, Saito M, Otsu K, Harada H, Yamada Y, Fukumoto S (2012) Role of epithelial-stem cell interactions during dental cell differentiation. J Biol Chem 287: 10590-10601.

Bluteau G, Luder HU, De Bari C, Mitsiadis TA (2008) Stem cells for tooth engineering. Eur Cell Mater 16: 1-9.

Branemark PI, Hansson BO, Adell R, Breine U, Lindstrom J, Hallen O, Ohman A (1977) Osseointegrated implants in the treatment of the edentulous jaw. Experience from a 10-year period. Scand J Plast Reconstr Surg Suppl 16: 1-132.

Caplan AI, Bruder SP (2001) Mesenchymal stem cells: building blocks for molecular medicine in the 21 st century. Trends Mol Med 7: 259-264.

Caton J, Bostanci N, Remboutsika E, De Bari C, Mitsiadis TA (2011) Future dentistry: cell therapy meets tooth and periodontal repair and regeneration. J Cell Mol Med 15: 1054-1065. 
Choi SW, Reddy P (2014) Current and emerging strategies for the prevention of graft-versus-host disease. Nat Rev Clin Oncol 11: 536-547.

Chrepa V, Henry MA, Daniel BJ, Diogenes A (2015) Delivery of Apical Mesenchymal Stem Cells into Root Canals of Mature Teeth. J Dent Res Jul 20. pii: 0022034515596527.

d'Aquino R, De Rosa A, Lanza V, Tirino V, Laino L, Graziano A, Desiderio V, Laino G, Papaccio G (2009) Human mandible bone defect repair by the grafting of dental pulp stem/progenitor cells and collagen sponge biocomplexes. Eur Cell Mater 18: 75-83.

de Mendonca Costa A, Bueno DF, Martins MT, Kerkis I, Kerkis A, Fanganiello RD, Cerruti H, Alonso N, PassosBueno MR (2008) Reconstruction of large cranial defects in nonimmunosuppressed experimental design with human dental pulp stem cells. J Craniofac Surg 19: 204-210.

Deepak BS, Nandini DB (2012) Stem cells: Challenges in endodontics. J Pharm Bioallied Sci 4: 84.

DeRosa TA (2006) A retrospective evaluation of pulpotomy as an alternative to extraction. Gen Dent 54: 37-40.

Di Scipio F, Sprio AE, Folino A, Carere ME, Salamone P, Yang Z, Berrone M, Prat M, Losano G, Rastaldo R, Berta GN (2014) Injured cardiomyocytes promote dental pulp mesenchymal stem cell homing. Biochim Biophys Acta 1840: 2152-2161.

Ding G, Liu Y, Wang W, Wei F, Liu D, Fan Z, An Y, Zhang C, Wang S (2010) Allogeneic periodontal ligament stem cell therapy for periodontitis in swine. Stem Cells 28: 1829-1838.

Du J, Shan Z, Ma P, Wang S, Fan Z (2014) Allogeneic bone marrow mesenchymal stem cell transplantation for periodontal regeneration. J Dent Res 93: 183-188.

Esposito M, Grusovin MG, Maghaireh H, Worthington HV (2013) Interventions for replacing missing teeth: different times for loading dental implants. Cochrane Database Syst Rev 3: CD003878.

Esposito M, Grusovin MG, Willings M, Coulthard P, Worthington HV (2007) Interventions for replacing missing teeth: different times for loading dental implants. Cochrane Database Syst Rev: CD003878.

Ferracane JL (2011) Resin composite - state of the art. Dent Mater 27: 29-38.

Friedenstein AJ, Chailakhjan RK, Lalykina KS (1970) The development of fibroblast colonies in monolayer cultures of guinea-pig bone marrow and spleen cells. Cell Tissue Kinet 3: 393-403.

Fron Chabouis H, Smail Faugeron V, Attal JP (2013) Clinical efficacy of composite versus ceramic inlays and onlays: a systematic review. Dent Mater 29: 1209-1218.

Fu X, Jin L, Ma P, Fan Z, Wang S (2014) Allogeneic stem cells from deciduous teeth in treatment for periodontitis in miniature swine. J Periodontol 85: 845-851.

Fuks AB (2008) Vital pulp therapy with new materials for primary teeth: new directions and treatment perspectives. J Endod 34: S18-24.

Gandia C, Arminan A, Garcia-Verdugo JM, Lledo E, Ruiz A, Minana MD, Sanchez-Torrijos J, Paya R, Mirabet V, Carbonell-Uberos F, Llop M, Montero JA, Sepulveda P (2008) Human dental pulp stem cells improve left ventricular function, induce angiogenesis, and reduce infarct size in rats with acute myocardial infarction. Stem Cells 26: 638-645.

Giannobile WV, Somerman MJ (2003) Growth and amelogenin-like factors in periodontal wound healing. A systematic review. Ann Periodontol 8: 193-204.

Giuliani A, Manescu A, Langer M, Rustichelli F, Desiderio V, Paino F, De Rosa A, Laino L, d'Aquino R, Tirino V, Papaccio G (2013) Three years after transplants in human mandibles, histological and in-line holotomography revealed that stem cells regenerated a compact rather than a spongy bone: biological and clinical implications. Stem Cells Transl Med 2: 316-324.

Graziano A, d'Aquino R, Laino G, Proto A, Giuliano MT, Pirozzi G, De Rosa A, Di Napoli D, Papaccio G (2008) Human CD34+ stem cells produce bone nodules in vivo. Cell Prolif 41: 1-11.

Gronthos S, Brahim J, Li W, Fisher LW, Cherman N, Boyde A, DenBesten P, Robey PG, Shi S (2002) Stem cell properties of human dental pulp stem cells. J Dent Res 81: 531-535.

Gronthos S, Mankani M, Brahim J, Robey PG, Shi S (2000) Postnatal human dental pulp stem cells (DPSCs) in vitro and in vivo. Proc Natl Acad Sci U S A 97: 1362513630.

Hayashi Y, Murakami M, Kawamura R, Ishizaka R, Fukuta O, Nakashima M (2015) CXCL14 and MCP1 are potent trophic factors associated with cell migration and angiogenesis leading to higher regenerative potential of dental pulp side population cells. Stem Cell Res Ther 6: 111.

Honda MJ, Shinohara Y, Hata KI, Ueda M (2007) Subcultured odontogenic epithelial cells in combination with dental mesenchymal cells produce enamel-dentin-like complex structures. Cell Transplant 16: 833-847.

Honda MJ, Sumita Y, Kagami H, Ueda M (2005) Histological and immunohistochemical studies of tissue engineered odontogenesis. Arch Histol Cytol 68: 89-101.

Howell TH, Fiorellini JP, Paquette DW, Offenbacher S, Giannobile WV, Lynch SE (1997) A phase I/II clinical trial to evaluate a combination of recombinant human platelet-derived growth factor-BB and recombinant human insulin-like growth factor-I in patients with periodontal disease. J Periodontol 68: 1186-1193.

Huang GT, Gronthos S, Shi S (2009) Mesenchymal stem cells derived from dental tissues $v s$. those from other sources: their biology and role in regenerative medicine. $\mathrm{J}$ Dent Res 88: 792-806.

Huang GT, Yamaza T, Shea LD, Djouad F, Kuhn NZ, Tuan RS, Shi S (2010) Stem/progenitor cell-mediated de novo regeneration of dental pulp with newly deposited continuous layer of dentin in an in vivo model. Tissue Eng Part A 16: 605-615.

Ikeda E, Tsuji T (2008) Growing bioengineered teeth from single cells: potential for dental regenerative medicine. Expert Opin Biol Ther 8: 735-744.

Iohara K, Imabayashi K, Ishizaka R, Watanabe A, Nabekura J, Ito M, Matsushita K, Nakamura H, Nakashima M (2011) Complete pulp regeneration after pulpectomy by transplantation of CD105+ stem cells with stromal cellderived factor-1. Tissue Eng Part A 17: 1911-1920. 
Iohara K, Murakami M, Takeuchi N, Osako Y, Ito M, Ishizaka R, Utunomiya S, Nakamura H, Matsushita K, Nakashima M (2013) A novel combinatorial therapy with pulp stem cells and granulocyte colony-stimulating factor for total pulp regeneration. Stem Cells Transl Med 2: 521533.

Jiang Y, Jahagirdar BN, Reinhardt RL, Schwartz RE, Keene CD, Ortiz-Gonzalez XR, Reyes M, Lenvik T, Lund T, Blackstad M, Du J, Aldrich S, Lisberg A, Low WC, Largaespada DA, Verfaillie CM (2002) Pluripotency of mesenchymal stem cells derived from adult marrow. Nature 418: 41-49.

Jin Q, Anusaksathien O, Webb SA, Printz MA, Giannobile WV (2004) Engineering of tooth-supporting structures by delivery of PDGF gene therapy vectors. Mol Ther 9: 519-526.

Kemoun P, Laurencin-Dalicieux S, Rue J, Farges JC, Gennero I, Conte-Auriol F, Briand-Mesange F, Gadelorge M, Arzate H, Narayanan AS, Brunel G, Salles JP (2007) Human dental follicle cells acquire cementoblast features under stimulation by BMP-2/-7 and enamel matrix derivatives (EMD) in vitro. Cell Tissue Res 329: 283-294.

Kerkis I, Ambrosio CE, Kerkis A, Martins DS, Zucconi E, Fonseca SA, Cabral RM, Maranduba CM, Gaiad TP, Morini AC, Vieira NM, Brolio MP, Sant'Anna OA, Miglino MA, Zatz M (2008) Early transplantation of human immature dental pulp stem cells from baby teeth to golden retriever muscular dystrophy (GRMD) dogs: Local or systemic? J Transl Med 6: 35.

Khorsand A, Eslaminejad MB, Arabsolghar M, Paknejad M, Ghaedi B, Rokn AR, Moslemi N, Nazarian H, Jahangir S (2013) Autologous dental pulp stem cells in regeneration of defect created in canine periodontal tissue. J Oral Implantol 39: 433-443.

Kitamura M, Akamatsu M, Machigashira M, Hara Y, Sakagami R, Hirofuji T, Hamachi T, Maeda K, Yokota M, Kido J, Nagata T, Kurihara H, Takashiba S, Sibutani T, Fukuda M, Noguchi T, Yamazaki K, Yoshie H, Ioroi K, Arai T, Nakagawa T, Ito K, Oda S, Izumi Y, Ogata Y, Yamada S, Shimauchi H, Kunimatsu K, Kawanami M, Fujii T, Furuichi Y, Furuuchi T, Sasano T, Imai E, Omae M, Yamada S, Watanuki M, Murakami S (2011) FGF-2 stimulates periodontal regeneration: results of a multicenter randomized clinical trial. J Dent Res 90: 35-40.

Kuroda R, Matsumoto T, Kawakami Y, Fukui T, Mifune Y, Kurosaka M (2014) Clinical impact of circulating CD34positive cells on bone regeneration and healing. Tissue Eng Part B Rev 20: 190-199.

La Noce M, Mele L, Tirino V, Paino F, De Rosa A, Naddeo P, Papagerakis P, Papaccio G, Desiderio V (2014) Neural crest stem cell population in craniomaxillofacial development and tissue repair. Eur Cell Mater 28: 348-357.

Lee CH, Cook JL, Mendelson A, Moioli EK, Yao H, Mao JJ (2010) Regeneration of the articular surface of the rabbit synovial joint by cell homing: a proof of concept study. Lancet 376: 440-448.

Lehmann N, Debret R, Romeas A, Magloire H, Degrange M, Bleicher F, Sommer P, Seux D (2009) Selfetching increases matrix metalloproteinase expression in the dentin-pulp complex. J Dent Res 88: 77-82.
Lemoli RM, Catani L, Talarico S, Loggi E, Gramenzi A, Baccarani U, Fogli M, Grazi GL, Aluigi M, Marzocchi G, Bernardi M, Pinna A, Bresadola F, Baccarani M, Andreone P (2006) Mobilization of bone marrow-derived hematopoietic and endothelial stem cells after orthotopic liver transplantation and liver resection. Stem Cells 24: 2817-2825.

Lovelace TW, Henry MA, Hargreaves KM, Diogenes A (2011) Evaluation of the delivery of mesenchymal stem cells into the root canal space of necrotic immature teeth after clinical regenerative endodontic procedure. J Endod 37: 133-138.

Lynch SE, Williams RC, Polson AM, Howell TH, Reddy MS, Zappa UE, Antoniades HN (1989) A combination of platelet-derived and insulin-like growth factors enhances periodontal regeneration. J Clin Periodontol 16: 545-548.

Magloire H, Romeas A, Melin M, Couble ML, Bleicher F, Farges JC (2001) Molecular regulation of odontoblast activity under dentin injury. Adv Dent Res 15: 46-50.

Mariotti A (1993) The extracellular matrix of the periodontium: dynamic and interactive tissues. Periodontol 2000 3: 39-63.

Martens W, Sanen K, Georgiou M, Struys T, Bronckaers A, Ameloot M, Phillips J, Lambrichts I (2014) Human dental pulp stem cells can differentiate into Schwann cells and promote and guide neurite outgrowth in an aligned tissue-engineered collagen construct in vitro. FASEB J 28: 1634-1643.

Mitsiadis TA, Feki A, Papaccio G, Caton J (2011) Dental pulp stem cells, niches, and notch signaling in tooth injury. Adv Dent Res 23: 275-279.

Mitsiadis TA, Graf D (2009) Cell fate determination during tooth development and regeneration. Birth Defects Res C Embryo Today 87: 199-211.

Mitsiadis TA, Rahiotis C (2004) Parallels between tooth development and repair: conserved molecular mechanisms following carious and dental injury. J Dent Res 83: 896902.

Mitsiadis TA, Woloszyk A, Jimenez-Rojo L (2012) Nanodentistry: combining nanostructured materials and stem cells for dental tissue regeneration. Nanomedicine (Lond) 7: 1743-1753.

Miura M, Gronthos S, Zhao M, Lu B, Fisher LW, Robey PG, Shi S (2003) SHED: stem cells from human exfoliated deciduous teeth. Proc Natl Acad Sci U S A 100: 5807-5812.

Morsczeck C, Gotz W, Schierholz J, Zeilhofer F, Kuhn U, Mohl C, Sippel C, Hoffmann KH (2005) Isolation of precursor cells (PCs) from human dental follicle of wisdom teeth. Matrix Biol 24: 155-165.

Muraglia A, Cancedda R, Quarto R (2000) Clonal mesenchymal progenitors from human bone marrow differentiate in vitro according to a hierarchical model. J Cell Sci 113 ( Pt 7): 1161-1166.

Naddeo P, Laino L, La Noce M, Piattelli A, De Rosa A, Iezzi G, Laino G, Paino F, Papaccio G, Tirino V (2015) Surface biocompatibility of differently textured titanium implants with mesenchymal stem cells. Dent Mater 31: 235-243.

Nakashima M, Iohara K (2014) Mobilized dental pulp stem cells for pulp regeneration: initiation of clinical trial. J Endod 40: S26-32. 
Nam H, Kim J, Park J, Park JC, Kim JW, Seo BM, Lee JC, Lee G (2011) Expression profile of the stem cell markers in human Hertwig's epithelial root sheath/ Epithelial rests of Malassez cells. Mol Cells 31: 355-360.

Nanci A (2012) Ten Cate's oral histology: development, structure, and function (8th edition). Mosby, USA, pp 1-13.

Nosrat IV, Widenfalk J, Olson L, Nosrat CA (2001) Dental pulp cells produce neurotrophic factors, interact with trigeminal neurons in vitro, and rescue motoneurons after spinal cord injury. Dev Biol 238: 120-132.

Oshima M, Tsuji T (2014) Functional tooth regenerative therapy: tooth tissue regeneration and whole-tooth replacement. Odontology 102: 123-136.

Otsu K, Kumakami-Sakano M, Fujiwara N, Kikuchi K, Keller L, Lesot H, Harada H (2014) Stem cell sources for tooth regeneration: current status and future prospects. Front Physiol 5: 36.

Pagella P, Neto E, Lamghari M, Mitsiadis TA (2015) Investigation of orofacial stem cell niches and their innervation through microfluidic devices. Eur Cell Mater 29: 213-223.

Peters OA (2014) Translational opportunities in stem cell-based endodontic therapy: where are we and what are we missing? J Endod 40: S82-85.

Pilipchuk SP, Plonka AB, Monje A, Taut AD, Lanis A, Kang B, Giannobile WV (2015) Tissue engineering for bone regeneration and osseointegration in the oral cavity. Dent Mater 31: 317-338.

Pisciotta A, Riccio M, Carnevale G, Lu A, De Biasi S, Gibellini L, La Sala GB, Bruzzesi G, Ferrari A, Huard J, De Pol A (2015) Stem cells isolated from human dental pulp and amniotic fluid improve skeletal muscle histopathology in mdx/SCID mice. Stem Cell Res Ther 6: 156.

Pittenger MF, Mackay AM, Beck SC, Jaiswal RK, Douglas R, Mosca JD, Moorman MA, Simonetti DW, Craig S, Marshak DR (1999) Multilineage potential of adult human mesenchymal stem cells. Science 284: 143-147.

Potdar PD, Jethmalani YD (2015) Human dental pulp stem cells: Applications in future regenerative medicine. World J Stem Cells 7: 839-851.

Prockop DJ (1997) Marrow stromal cells as stem cells for nonhematopoietic tissues. Science 276: 71-74.

Ricketts D (2001) Management of the deep carious lesion and the vital pulp dentine complex. Br Dent J 191: 606-610.

Ripamonti U (2007) Recapitulating development: a template for periodontal tissue engineering. Tissue Eng 13: 51-71.

Sankaranarayanan S, Jetty N, Gadagi JS, Preethy S, Abraham SJ (2013) Periodontal regeneration by autologous bone marrow mononuclear cells embedded in a novel thermo reversible gelation polymer. J Stem Cells 8: 99-103.

Selvig KA, Sorensen RG, Wozney JM, Wikesjo UM (2002) Bone repair following recombinant human bone morphogenetic protein-2 stimulated periodontal regeneration. J Periodontol 73: 1020-1029.

Seo BM, Miura M, Gronthos S, Bartold PM, Batouli S, Brahim J, Young M, Robey PG, Wang CY, Shi S (2004) Investigation of multipotent postnatal stem cells from human periodontal ligament. Lancet 364: 149-155.
Sonmez IS, Akbay Oba A, Erkmen Almaz M (2013) Revascularization/Regeneration performed in immature molars: case reports. J Clin Pediatr Dent 37: 231-234.

Sonoyama W, Liu Y, Fang D, Yamaza T, Seo BM, Zhang C, Liu H, Gronthos S, Wang CY, Wang S, Shi S (2006) Mesenchymal stem cell-mediated functional tooth regeneration in swine. PLoS One 1: e79.

Sonoyama W, Liu Y, Yamaza T, Tuan RS, Wang S, Shi S, Huang GT (2008) Characterization of the apical papilla and its residing stem cells from human immature permanent teeth: a pilot study. J Endod 34: 166-171.

Sonoyama W, Seo BM, Yamaza T, Shi S (2007) Human Hertwig's epithelial root sheath cells play crucial roles in cementum formation. J Dent Res 86: 594-599.

Sudo K, Kanno M, Miharada K, Ogawa S, Hiroyama T, Saijo K, Nakamura Y (2007) Mesenchymal progenitors able to differentiate into osteogenic, chondrogenic, and/ or adipogenic cells in vitro are present in most primary fibroblast-like cell populations. Stem Cells 25: 1610-1617.

Takahashi K, Yamanaka S (2006) Induction of pluripotent stem cells from mouse embryonic and adult fibroblast cultures by defined factors. Cell 126: 663-676.

van den Akker F, de Jager SC, Sluijter JP (2013) Mesenchymal stem cell therapy for cardiac inflammation: immunomodulatory properties and the influence of toll-like receptors. Mediators Inflamm 2013: 181020.

Veis A, Tompkins K, Alvares K, Wei K, Wang L, Wang XS, Brownell AG, Jengh SM, Healy KE (2000) Specific amelogenin gene splice products have signaling effects on cells in culture and in implants in vivo. J Biol Chem 275: 41263-41272.

Volponi AA, Pang Y, Sharpe PT (2010) Stem cell-based biological tooth repair and regeneration. Trends Cell Biol 20: 715-722.

Waddington RJ, Youde SJ, Lee CP, Sloan AJ (2009) Isolation of distinct progenitor stem cell populations from dental pulp. Cells Tissues Organs 189: 268-274.

Wang L, Shen H, Zheng W, Tang L, Yang Z, Gao Y, Yang Q, Wang C, Duan Y, Jin Y (2011) Characterization of stem cells from alveolar periodontal ligament. Tissue Eng Part A 17: 1015-1026.

Weissman IL, Anderson DJ, Gage F (2001) Stem and progenitor cells: origins, phenotypes, lineage commitments, and transdifferentiations. Annu Rev Cell Dev Biol 17: 387-403.

Windisch P, Stavropoulos A, Molnar B, Szendroi-Kiss D, Szilagyi E, Rosta P, Horvath A, Capsius B, Wikesjo UM, Sculean A (2012) A phase IIa randomized controlled pilot study evaluating the safety and clinical outcomes following the use of rhGDF-5/beta-TCP in regenerative periodontal therapy. Clin Oral Investig 16: 1181-1189.

Yang KC, Wang CH, Chang HH, Chan WP, Chi CH, Kuo TF (2012) Fibrin glue mixed with platelet-rich fibrin as a scaffold seeded with dental bud cells for tooth regeneration. J Tissue Eng Regen Med 6: 777-785.

Yokoi T, Saito M, Kiyono T, Iseki S, Kosaka K, Nishida E, Tsubakimoto T, Harada H, Eto K, Noguchi T, Teranaka T (2006) Establishment of immortalized dental follicle cells for generating periodontal ligament in vivo. Cell Tissue Res 327: 301-311. 
Zhang W, Chen J, Tao J, Jiang Y, Hu C, Huang L, Ji J, Ouyang HW (2013) The use of type 1 collagen scaffold containing stromal cell-derived factor- 1 to create a matrix environment conducive to partial-thickness cartilage defects repair. Biomaterials 34: 713-723.

Zhao H, Feng J, Seidel K, Shi S, Klein O, Sharpe P, Chai Y (2014) Secretion of shh by a neurovascular bundle niche supports mesenchymal stem cell homeostasis in the adult mouse incisor. Cell Stem Cell 14: 160-173.

Zheng Y, Wang XY, Wang YM, Liu XY, Zhang CM, Hou BX, Wang SL (2012) Dentin regeneration using deciduous pulp stem/progenitor cells. J Dent Res 91: 676682 .

\section{Discussion with Reviewer}

Jean Christophe Farges: What might be the most important hurdles and limits of regenerative endodontics in the future?

Authors: As in every dental speciality, since no generally accepted standardised protocol concerning therapies using stem cells in dentistry is available, the approaches may be very variable and as a result, the outcomes can be variable as well. For this reason, the most significant hurdles and limitations include:

1. Standardisation of clinical operation protocols for endodontic treatments using stem cells

2. Sources and standardisation of stem cells for use in clinics

3. Adaptation of endondontic techniques according to the specific anatomical shape of the roots, volume of the pulp chamber, age of the patient, status of the general health of the patient

4. Necessity of post-operative follow up

5. Cost of the treatment

6. Specialised manufactures (industrialisation) for covering large-scale treatment for all individuals

Editor's Note: Scientific Editor in charge of the paper: Juerg Gasser. 